\title{
Readibility of Folklor Published by Agency Development and Language Development Ministry of Education and Culture
}

\author{
Annisa'ul Mufidah \\ Universitas Negeri Surabaya \\ Surabaya, Indonesia \\ annisaulmufidah@mhs.unesa.ac.id
}

\author{
Kisyani Laksono \\ Universitas Negeri Surabaya \\ Surabaya, Indonesia \\ kisyanilaksono@unesa.ac.id
}

\author{
Setya Yuwana \\ Universitas Negeri Surabaya \\ Surabaya, Indonesia \\ setyayuwana@unesa.ac.id
}

\begin{abstract}
This purpose of research to determine the level of readibility of folklore published by the agent language using three measuring instruments, namely fry graph, word association, and cloze test. This research type is quantitative and qualitative with descriptive method. The subjects of the study were the students of grade IV, V, and VI SDN Kemuningsari Kidul 01, and grade 6 students of SDN Kertonegoro 04. Data collection technique used is documentation for fry graph, word association test, and cloze test. The results of the fry graph, word association, and cloze test are the scores described and the data analyzed in the form of descriptions. The result of the analysis of the 32 book, readibility of folklore published by the agent of language, folklore "Sumur Keramat Jati Herang" and "Cerita Datuk Termiang Belah" book that can be read and understood by grade VI students. 6 books can be used for students of class VI, but aided, and 1 book can be read by grade IV students with help. While the other 23 books are not suitable with students because it is difficult to read and understand students.
\end{abstract}

Keywords—readibility, fry graph, word association, cloze test

\section{INTRODUCTION}

School Literacy Movement was formed to strengthen the movement of moral character as stated in the Regulation of the Minister of Education and Culture No. 23 of 2015. From the regulation activities in the movement is to read non-lesson books before learning for 15 minutes. Literacy Movement is implemented based on the results of Program for The International Student Assessment (PISA) of 2015 [1] in its research involving 540,000 students from representatives of 72 countries, shows that Indonesian students' reading ability is ranked 66th out of 72 countries surveyedbu OECD The 15 minute activity of reading non-lesson book is done to foster reading interest of learners and improve reading skill so that knowledge can be mastered better. Reading materials contain the values of character, in the form of local, national, and global wisdom that is delivered according to the stage of development of learners.
The reading material in accordance with the School Literacy Movement program is the literary work especially the story. Literary works are very close to the world of children because the world of children is full of imagination. With literature, the imaginary world of children can be represented. Kurniawan [2] explains there are two positions of literary work on child development. First is the love of children to the literary work can improve the hobby of children in reading, which in turn can make children accustomed to reading, reading habits is the key of mastering science. The second is to read an literary work intensely capable of providing a complex intelligence of children, namely cognitive, psychomotor and affective because in the literary work contained moral values that are useful for the development of children's thoughts and feelings.

Most of the folklore books for high grade IV, V and VI. The determination of the ladder is already listed on the cover of the book. However, some books do not include their class identity, so it needs to be investigated further

Education and Culture Ministerial Regulation No. 8 of 2016 [3] on books used by educational unit, subsection 3, paragraph 6 , explained that non-teaching lesson book must fulfill the material aspect, and can also add linguistic aspects, aspects of material presentation, and graph aspect. Aspects researched by the researchers here is the language aspect. Researchers are interested to examine the language aspect because in the linguistic aspect the researcher will examine how the language used in discourse of folklore so that the reader is able to understand the positive message conveyed, has the character of educative, courteous, ethical, and aesthetically in accordance with the level of age development. The use of the language used by the author will have an effect on the readability of the text.

Subject to the reading of a text quickly and easily, and easily understood by the meaning contained in the text in a large Indonesian dictionary is defined as legibility [4]. Readability is related to the field of reading by considering the 
difficulty level of a text or the content of the text with the reader. Beaglehole [5] also explained that Readability refers to the ease of text to read. When the readability of the text is high then the moral message contained in the folklore can be understood by students, and can be applied in everyday life.

The essence of readability is very important to be known by an educator because educators are required to become a facilitator in transferring knowledge so as to know the suitability of materials to be used before transferred to learners. To analyze the legibility according to Asem [6] there are two approaches: qualitative and quantitative analysis. Quantitative analysis is the test of legibility based on linguistic aspects such as the length of words and sentences which then dikutung using legibility formula. For a qualitative analysis of reading the readability of the reader's characteristics. For the analysis to be used in this study is a quantitative analysis using the formula legibility.

Quantitative readability analysis relates two things: the whole element in the text as well as the reading material. There are two factors that affect the legibility of the length and shortness of the sentence and the degree of difficulty of the word. There are several legibility formulas that use the twofactor readability benchmark. it is useful to evaluate all components of the textbook section to show how far the reader reads the text at optimum speed, and understands its meaning. Berndt [7] mentions that such formulas are Flesch, Fog Index, SM-OG, Fry Graph, and cloze tests.

The problem of readibility in reading learning is less gaining attention by some teachers. Some teachers do not yet know which measurement tool can be used to determine the level of text readability. In addition, teachers have not been able to measure the level of legibility of the text. So they only give textbooks issued by the government to students without knowing the suitability of the book with their students. As a result there is a gap between the text that is read with the students' understanding. This gap makes it difficult for students to understand the meaning of the readings.

This research is intended to describe the results of content analysis about the legibility of folklore texts. This readability analysis is performed using fry graphs, cloze tests, and word association tests. By using the three measuring tools are expected to obtain valid results researchers in measuring the legibility of folklore text. Graphic fry is a legibility formula that does not involve learners. Graph fry is used to find out the suitability of folklore text with a certain level of class. In accordance with the previous explanation that the cover of the folklore book has not specifically included the identity of the class, so here the researcher wants to describe the class identity specifically to help teachers and parents. . The word association test is used to find out the extent to which the student's early knowledge of the story book is read. The last test used to measure readability is the cloze test. The cloze test is used to determine the level of difficulty of the folklore text

Folklore is a story that is lifted from from a certain area to describe the area. Folklore describes the characteristics of each region. Folklore presents various stories. There are folktales that tell human stories with fellow human beings, folktales that tell people about the surrounding natural environment, or folklore that tells the human story with God. The work of fiction literature was written by the author to introduce the idealized model of life. Fiction contains a moral application in the attitude and behavior of the characters in accordance with his view of moral [8]. Literary works created as guides of human life is very important to be studied and also as a planting value of moral values to human relationships. The cultivation of moral values can be accepted by the learner if the student is able to understand the contents of the folklore text he reads.

The government issued this folklore book in addition to increasing interest in reading students as well as to instill moral values through the stories that are in it. This moral value can be accepted by readers or students if the legibility of the book in accordance with the level of class and their abilities. The planting of moral values can be taught, through examples in the story, they can reflect on their lives. Rahim [9] argues stories are very effective at modeling, discussing matters of morality, and potentially contributing significantly to the moral education of children and adults.

The reason for choosing the text of the folklore to be examined legibility because no one has examined the legibility of the text of the folklore issued by the language body, in addition there is a critique of folklore issued by the language body, one of the criticisms expressed by one of the Research Agency Development and Development An unnamed language, the criticism was published via suarapembaca.net dated March 12, 2017, the researcher said that the standard legibility of the story still needs to be evaluated.

There is a major essence that must be considered that the rewriting of folklore is directed to the child by considering the age of the learners according to their level of development. they and the re-writing of folklore do not deprive the essence of moral values as its main asset. This moral value will be dug and taught to the child that our education side with the child and achieve the goal as a means of forming the character of the nation. Therefore, researchers interested in researching legibility in folklore, so that students are able to read and understand the contents of the folklore well

It is hoped that this research can generate a critical outlook for teachers in choosing the appropriate reading with their level of ability, and address the moral values contained in folklore. Parents of course want to give the best for their children from an early age.

Based on the explanation and to obtain a description of the legibility and moral values contained in folklore, researchers need to conduct research entitled "Readibility of Folklore published by Agency Development and Language Development Ministry of Education and Culture"

\section{A. Benefit of Research}

Theoretically this research is useful for developing science in the field of linguistics, especially in the field of text readability. In the field of this legibility, the results of this study contribute knowledge about the appropriateness of folklore textbooks according to their level. 
In practical terms this research is useful for elementary school students, teachers in elementary schools, other researchers and team of language agency kemendikbud who has published books folklore. For elementary school students this research can increase reading interest.

For primary school teachers the results of this study are able to provide input in selecting reading books that are appropriate to the level of students' ability and teach moral values. For other researchers able to assist in deepening the concept of legibility, especially at elementary school level. In addition, as input for the team of language agencies kemendikbud to evaluate and develop books reading by paying attention to the quality of legibility and moral planting in it.

\section{RESEARCH METHODS}

This research uses quantitative-qualitative approach with descriptive research type. Quantitative approach is used to identify readibility. Qualitative approach is used to describe the results of readibility test. This type of research is descriptive because the research describes the results of anaisis readibility using fry graphs, cloze tests, and word associations.

The research data are numbers based on the short length of words analyzed by fry graph, the result data of word association test and cloze test.

The data source is the number of words and syllables for the fry graph, the word association test is sourced from the student's initial knowledge, and the cloze test comes from the text of the story being superimposed. The sample used is 32 storybooks that represent each province.

Data collection techniques used are documentation techniques for data collection of the number of syllables and sentences per 100 words. As well as test techniques used to collect data score test results of word associations and cloze tests.

The data collection instruments used are sheets of syllables and sentences in a hundred words, sheets of word association tests and sheets of analysis results of word association tests, for cloze tests, the instruments are cloze test sheets, answer sheets, and cloze test sheets.

\section{DISCUSSION}

\section{A. Readibility Based on Fry Graph}

The Fry graph is used to analyze the fit of the folklore book with a particular class. The sample used in this study amounted to 32 pieces of story books. To use the fry graph the folklore text is analyzed first using the documentation technique to determine the number of 100 words. Folklore book is thick, then the measurement of legibility is done as much as 3 times, namely the beginning of the book, the middle of the book, and the end of the book. From the third measurement result is then calculated average for each number of sentences and syllables. From the third measurement result is then calculated average for each number of sentences and syllables. After the number of sentences and syllables of 100 words is found, the next step is to count the number of sentences and syllables contained in 100 words.

Based on the analysis of the number of sentences and syllables that are then analyzed using the graph fry found that there is 1 book suitable for level 3, 1 book suitable for level 4 , 5 books suitable for level 5, 6 books suitable for level 6, 16 books suitable for level 7 , and 3 books suitable for level 8 .

The results of this fry graph can be approximate, so the fry graph can be added one level and minus one level. For books calculated using the fry erada graph at level 3, the approximate book is suitable for $2 \mathrm{nd}, 3 \mathrm{rd}$, and 4 th grade students. Similarly for books in levels $4,5,6,7$, and 8 .

Fry graph analysis results can also be described using a table to make it easier for readers to understand the results of the research. Here is an overview of the results of readibility of folklore books analyzed using the fry graph.

TABLE I. LEVEL OF READIBILITY ANALYZED BY FRY GRAPH

\begin{tabular}{|c|c|c|c|c|c|c|}
\hline No. & \multicolumn{7}{|c|}{ Level } \\
\hline & 3 & 4 & 5 & 6 & 7 & 8 \\
\hline Total & 1 & 1 & 5 & 6 & 7 & 8 \\
\hline
\end{tabular}

\section{B. Readibility Based on the Word Association Test}

The word association test serves to determine the initial knowledge of a reader. In this study, word association tests are used to determine the extent to which the initial knowledge of the students or the extent to which students know the topic of folklore to be read.

The word association test is given by distributing the word association test sheets that have the topic of each story to the students, where in each test sheet there are 10 words or phrases that must be written by the students. The time to do each test is for 3 minutes. This test is performed in classes IV, $\mathrm{V}$, and VI with a sample size of 32 pieces of story. In accordance with the results of the fry graph there are 2 stories to be tested in class IV, 5 stories in class V, and the last 25 stories will be tested in class VI.

The word association test is tested on grade VI students. The story book is tested in class VI as many as 25 story books. Due to the number of story books that many researchers use 2 rombel class VI, 2 classes are located in two schools in Jember, with the number of students of class VI as many as 24 people, in the class divided into 3 groups, with the number of each group as many as 8 people. Each group is given 3 pieces of reading or 3 pieces of word association tests. While at the scond schoolthe number of students 36 students. In the class is divided into 4 groups with each group of 9 students, with each group is given 4 pieces of reading or 4 pieces of word association tests. The result of the association test as shown in the following table.

Here the results of word association tests are described in tabular form to make it easier for readers to read and understand the results of the study. 
TABLE II. LEVEL OF READIBILITY ANALYZED BY WORD ASSOCIATION TEST

\begin{tabular}{|c|c|c|c|}
\hline \multirow{2}{*}{ Class } & \multicolumn{3}{|c|}{ Level } \\
\cline { 2 - 4 } & Low level & Medium Level & High Level \\
\hline 4 & 1 & 1 & 0 \\
\hline 5 & 5 & 0 & 0 \\
\hline 6 & 10 & 15 & 0 \\
\hline
\end{tabular}

\section{Readibility Based on Cloze Test}

The third analysis used to measure legibility is to use a cloze test. This cloze test is used to assess textual readability as well as to measure the extent to which students understand the text being read. The cloze test was given to students of grade IV, V and VI with book sample of 32 books. A total of 2 books were tested to fourth graders, each with 30 minutes of each test.

The results of the cloze test in class IV indicate that both books are at a frustrating level because the result is less than 44. The score explains that story books number 99 and 95 are less suitable for fourth grade students.

Based on the test results cloze tested in the 5th grade that the five books are following the final score below 44. The results of the cloze test indicates that the book is less readable or at the level of frustration.

The test of cloze tested in class VI is 25 test based on Graph Fry result. For class VI researchers used two classes consisting of 2 schools as a place of study. The first Class VI is located at SDN Kertonegoro 4 with a total of 24 students and 9 cloze test, while the second class VI is located at SDN Kemuningsari Kidul 01 with 36 students and 16 cloze test.

The test of class VI cloze at first schoolwas divided into 3 groups of students as many as 24 students. Each group numbered 8 people. With each group getting 3 cloze tests. The following test results cloze group 1

The second table below illustrates the results of class VI cloze test group 2 at the first school

The second grade cloze test was then held at the second school. The number of students in the elementary school was 36 students. Class VI is divided into 4 groups with the number of each group is 9 students. Each group received 4 cloze tests. Here are the results of the cloze test for the group at SDN Kemuningsari Kidul 01.

Cloze test results can be described using tables to facilitate the reader in understanding the data of research results. Here is an overview of cloze test results in tabular form.

TABLE III. LEVEL OF READIBILITY ANALYZED BY CLOZE TEST

\begin{tabular}{|c|c|c|c|}
\hline \multirow{2}{*}{ Class } & \multicolumn{3}{|c|}{ Level } \\
\cline { 2 - 4 } & Independent & Instruksional & Frustration \\
\hline 4 & 0 & 0 & 2 \\
\hline 5 & 0 & 0 & 5 \\
\hline 6 & 1 & 1 & 23 \\
\hline
\end{tabular}

\section{RESULT}

\section{A. Folklor Adequacy with The Results Obtained}

There are differences in the results of the three measuring instruments between the fry graph, the word association test, and the cloze test. The fry graph is based on the number of syllables and the number of sentences, the fry graph is based that the longer a sentence and the number of syllables are many then the text is increasingly difficult to read, and influences the students in reading interest. When a text is hard to read then the text has low readability.

The use of fry graphs to determine the level of readability by considering the number of sentences and syllables only consider the text surface structure alone by ignoring the internal factors of the reader. Therefore, in this study there are differences in fry graph results with the results of the word association test and also the cloze test.

There are several factors that influence a person in understanding a reading. These factors include cultural differences, author and reader background, language and language code, and differences in assumptions [10]. This is evident from the results of research on the word association test and also the test cloze on some story books that show low results and not in accordance with the results of the graph fry. This is because the background of different authors and the reader, culture, and language code that is not understood by students so that students are difficult to understand the text of the story. In addition, the ability to read, the concentration of students while doing also affect the test results.

\section{B. Consideration of Use of Means of Graph Fry, Word Assosiation Test, and Cloze Test}

The use of fry graphs, word association tests, as well as cloze tests as a legibility measurement tool used by researchers based on various considerations. The fry graph uses the number of syllables and the number of sentences in calculating the degree of legibility. The use of the fry readsheet formula only looks at the surface structure only by ignoring the concepts contained in the reading as the reading structure. If a sentence looks long, then the sentence is quite difficult, otherwise if the sentence is short, then the sentence is quite easy. The fry graph is used to view the level of readability by not paying attention to the semantic elements in the reading. However, the advantage of this fry graph is the ease of calculation.

The second measuring tool is a word association test used to determine the initial ability of students in understanding the text to be read. The reason for using this test is that it is easy to measure knowledge or memories, easy to work, and match answers with folklore books. The weakness of a word association test is difficult in its judgment if students' answers contain the correct variety of words.

Cloze technique also has advantages. The first advantage is that this test has an interaction between the reader and the author, both of these tests can serve as a measuring tool to know the knowledge and understanding of students and can be used as training readiness and responsiveness of students in understanding the purpose of the author. 
The disadvantage of a cloze test is the accuracy of the student's answer to fill the stacked section, the student tends to populate the portion that is superimposed using familiar expression patterns, rather than on the suitability of the word with the missing word.

Various considerations have been described previously in determining the appropriate measuring tool in measuring legibility, the next researchers are expected to be more selective in choosing the right measuring instrument to replicate readability by considering the advantages and disadvantages of each measuring instrument.

Based on the feasibility aspects of the book, the content feasibility, language and legibility, presentation, and kegrafikan, folklore books published this language body still needs to be reviewed and revised because it has not fulfilled the legibility aspect.

\section{CONCLUSION AND SUGGESTION}

\section{A. Conclusion}

The legibility of folklore books is based on three measuring instruments: fry graph, word association test, and cloze test. Based on the results described previously, the folklore book that is suitable for students to read and understand is the folklore book numbered 21 and the 17th numbered book. Although in the calculation of the number of syllables and the number of sentences of the book is ranked at level 7, which means the book fits used at levels 6,7 and 8 . But the results of the initial knowledge test on book number 21 shows a score of 51.25 which means students can understand the reading with help, supported by the results of cloze tests showed a score of 61.25 which means students can membca the book in independent. For book number 17 the preliminary knowledge test result shows 76.3 which means the students can comprehend the reading, and the cloze test result shows the score 44,17 which means the student is able to read the book but with the help.

\section{B. Suggestion}

Based on the results of research, there are several suggestions that researchers can provide. First advice is directed to teachers, especially high class 4, 5 and 6. Teachers should provide reading books in accordance with the ability to read students so that students are easy to read and the content in the book can be understood by students.

Second, suggestions addressed to further researchers. To the next researcher this research can be used as reference to research about keterbacaam to be more specific and effective so that result more accurate.

Third, the suggestion for the linguistic body as the publisher of folklore books to revise the folklore book is tailored to the students' abilities.

Based on the standard of book assessment, a good book should meet 4 aspects of content feasibility, language feasibility and legibility, feasibility of presentation and feasibility of kegrafikan. This study focuses on feasibility of legibility. The results show that the storybook is less suitable with the ability of fourth grade students, V and VI in sample schools. Therefore, the folklore book needs to be reviewed and revised in accordance with the needs of students who are useful to improve the quality of books darri aspect readability contained in folklore books.

\section{REFERENCES}

[1] Programme For International Student Assessment (PISA) Result From PISA, 2015

[2] H. Kurniawan, Sastra Anak dalam Kajian Striukturalisme, Sosiologi, semiotika, dan Penulisan Kreatif. Yogyakarta: Graha Ilmu, 2009.

[3] Peraturan Menteri Pendidikan Dan Kebudayaan Republik Indonesia Nomor 8 Tahun 2016 Tentang Buku yang Digunakan oleh Satuan Pendidikan.

[4] Departemen Pendidikan Nasional, Kamus Besar Bahasa Indonesia Jakarta: PT Gramedia, 2008

[5] V.J. Beaglehole, "The Full Stop Effect: Using Readability Statistics with Young Writers," Journal of Literacy and Technology, vol. 11, pp. 54-83, 2010 .

[6] B. Asem, "Evaluation Of Textual Readibility An Analysis of Its Varying Approaches," International Journal Of Research In Humanities, Arts, And Literature, vol. 1, pp. 7-12, 2013.

[7] Berndt , Adele, and J.P. Wayland, "Evaluating The Readability of Marketing Research Textbooks: An International Comparison," Journal of International Educationin Business, vol. 7, pp.47-59, 2014.

[8] B. Nurgiyantoro, Teori Pengkajian Fiksi. Yogyakarta:Gadjah Mada University Press, 2002.

[9] Rahim, Husni \& M.D.H. Rahiem, "The Use Stories as Moral Education for Young Children," International Journal of Social Science and Humanity, vol. 2, pp. 454-458, 2012.

[10] M.F. Baradja, Kapita Selekta Pengakaran Bahasa. Malang: IKIP Malang, 1990 